\title{
Stresses in Wall of Ferrocement Silo using Finite Element Model
}

\author{
C. P. Patel, Sunil Kute, P. D. Patil, Renuka Jain
}

\begin{abstract}
Ferrocement is one of the most inexpensive and alternative construction techniques. The beauty of this materials attracts in analyzing and designing the ferrocement (F.C.) silo. This has encouraged the search for new materials like F.C. to provide an alternative to reinforced concrete. During last two decades, many attempts have been made to develop computational models for analysis of silos particularly in steel and reinforced cement concrete. However, very less work is reported on scientific development of analysis of F.C. silo. This indicates that there is a need to continue with more focus and detailed research on F.C. silo. There is a need to analyze F.C. silo for various parametric findings related to pressure and behavior of silo in tension, compression and flexure. Present paper reports new aspects of analysis of silo. The parametric study of stresses developed in wall of F.C. silo for different H/D ratio, thickness and storage capacity is done with help of commercial ANSYS version R14.5.

Keywords: Wall stresses, Wire mesh, Ferrocement silo, Structural analysis.
\end{abstract}

\section{INTRODUCTION}

The concrete technologist is facing with the problem of improving the inherent properties of concrete composites in order to fulfil the designer's requirements. This encouraged the search for new materials like ferrocement to replace reinforced concrete. The industrial world depends on handling operations of bulk solids to a very large extent. As bulk tonnages increase, there is an ongoing need for more efficient, higher capacity storage and transport systems. In turn, more sophisticated analysis and design procedures are a continuing necessity. Some significant developments in ferrocement silo is the need of future of the various industrial world. Ferrocement, over the year have gained structural

Revised Manuscript Received on April 25, 2020.

* Correspondence Author

C. P. Patel.*, Ph.D. Research Scholar, Department of Civil Engineering, North Maharashtra University, Jalgaon.425401, Maharashtra, India e-mail: vastudhan@gmail.com

Sunil Kute, Professor, Department of Civil Engineering K. K. Wagh Institute of Engineering Education and Research, Nasik.422003 Maharashtra India, e-mail: sunil_kute@rediffmail.com

P.D. Patil, Principal, Jayakumar Raval Institute of Technology Donnacha, Maharashtra, India. e-mail: pdpatilco@rediffmail.com

Renuka Jain, Under graduate student, Department of Civil Engineering College of Engineering Shahada, Maharashtra, India, e-mail: renukajain9917@gmail.com

(C) The Authors. Published by Blue Eyes Intelligence Engineering and Sciences Publication (BEIESP). This is an open access article under the CC BY-NC-ND license (http://creativecommons.org/licenses/by-nc-nd/4.0/) popularity in term of its superior performance and versatility. [1] It is not only preferred in housing industry but its potential is being continuously explored for its industrial use. Ferrocement is more durable, the skills for ferrocement construction can be easily acquired. The fabrication process of ferrocement is simple; it requires no formwork; it requires no skilled labours, and construction to any complicated shape is possible which cannot be easily done with standard masonry, reinforces concrete or steel. Ferrocement is one of the most inexpensive and alternative construction techniques.

The beauty of this materials attracts in analyzing and designing the ferrocement silo. [2,3] Each year, an alarming number of silos fail due poor analysis and design. Many failures are due to loading conditions which are not considered by the designer. Various codes which are used worldwide, does not cover many common load cases. A comprehensive literature survey indicates a need of analysis to reduce the overall cost of silo and enhance the stability.

During the last two decades, many attempts have been made to develop computational models to represent the analysis of in silos particularly in Steel as well as reinforced cement concrete. However, very less work is reported on scientific development of analysis of ferrocement silo. This indicates that there is a need to continue with more focus and detailed research on ferrocement silo. The analysis of ferrocement silo is unique because very little technical information is available on features of ferrocement silo. It is a very much need to analyze ferrocement silo numerically, so that the various parametric findings regarding pressure developed in accordance with tension, compression and flexure may be taken in to account. In this report presents a "Finite element model for the analysis of ferrocement silos using the capacities of the ANSYS R14.5 software.

\section{EXISTING THEORIES / METHODS FOR SILO ANALYSIS}

Classical research has classified the pressures on the wall of silos as static and dynamic. For many years, research on the prediction of silo pressure was mainly governed by analytical methods, numerical methods and experimental.

\subsection{Analytical methods}

Since late $19^{\text {th }}$ century, a variety of analytical formulae have been developed for the prediction of bulk material pressures on wall of silos such as Janssen's theory, Walker theory, Walters theory, Jenikes theory. Janssen's theory (Janssen 1895) is widely used for static pressure in silo though it is not predicting emptying pressure.

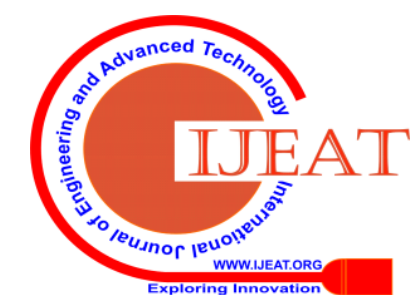


[4] In present paper, the Janssen's theory is used to calculate various stresses resulting for static condition, based on static equilibrium of a slice of granular material stored in circular silo with help of following equation.

$$
\begin{aligned}
& \mathrm{P}_{\mathrm{h}}=\frac{\mathrm{YR}}{\mu}\left[1-\mathrm{e}^{(-\mu \mathrm{h} / \mathrm{R})}\right] \\
& \mathrm{P}_{\mathrm{V}}=\frac{\mathrm{YR}}{\mu \mathrm{k}}\left[1-\mathrm{e}^{(-\mu \mathrm{h} / \mathrm{R})}\right] \\
& \mathrm{k}=\frac{1-\sin \emptyset}{1+\sin \emptyset}
\end{aligned}
$$

where $-\mathrm{P}_{\mathrm{h}}=$ Horizontal pressure at depth $\mathrm{h}\left(\mathrm{kN} / \mathrm{m}^{2}\right) ; \gamma=$ Specific weight of material stored $\left(\mathrm{kN} / \mathrm{m}^{3}\right)$; $\mathrm{R}=$ Hydraulic mean depth.is defined as ratio of the cross-sectional area of the silo to the perimeter of silo $(\mathrm{m})$; $\mathrm{K}=$ the ratio of lateral to vertical pressure $\left(\mathrm{P}_{\mathrm{h}} / \mathrm{P}_{\mathrm{v}}\right) ; \mu=$ coefficient of friction of stored material on the bin wall; $h=$ depth from the surface of material(m); $\mathrm{P}_{\mathrm{v}}=$ vertical pressure at depth $\mathrm{h}, \phi=$ angle of repose.

\subsection{Experimental methods}

In addition to analytical approach, many experimental studies have been performed to evaluated the pressure on wall of silos. [5] Most experiments are conducted on models of silos. However, several tests of pressure on actual silos have also been reported to calculate the pressure developed due to grains in silo. Apparently, experimental research is essential for getting the primary idea of pressure distribution on walls of silos.

\subsection{Numerical methods}

Due to potential in solving problems of complicated geometry recently some researchers have attained their interest to numerical modeling. [6,7,8]. Also, focused on simulation of complex behavior of stored bulk material in silos. Several attempts to use the finite element method to predict bulk material pressure on the walls of silo have been reported.

\section{METHODOLOGY}

The study of existing designing method applied to silo is used to design and analyze the F.C. silo, because the behavior of F.C. silo and interaction with the material is differed. Identification the limit of existing silo design, the design of F.C. silo can be done to new design aspects. For that conducting parametric study on performance for F.C. silo on the basis of parameter such as tension, compression and flexure. It is required to develop totally new design criteria by analyzing F.C. silo. While analyzing F.C. silo various dimensional parameter such as H/D ratio, storage capacity, steel requirement and durability aspect have been considered. The F.C. silo was design for static condition only. The result obtained by numerical approach are validated with the results obtained by other researcher using software approach.

\section{MODELLING AND ANALYSIS}

The main objective of this research paper was to analyze silo using the finite element method as a tool. Silo was modelled in 3-D modelling software CREO, version 3.0. ANSYS workbench 19.2 educational version and file of 3-D model was imported in ANSYS. Ferrocement was modelled in material library to impart the various properties. The loads were applied in the form of pressure loads with horizontal and vertical components.[9] The hoop stress was modelled as normal stress in cylindrical radial direction and longitudinal stress as normal stress in vertical direction. Following input parameters were considered for the analysis is shown in Table 1.

Table- I: Input Parameter for analysis [1].

\begin{tabular}{|l|l|}
\hline Parameter & Value \\
\hline $\begin{array}{c}\text { Cefficient of friction between cement } \\
\text { powder and silo wall }(\mu)\end{array}$ & 0.554 \\
\hline Specific weight of cement powder $(\gamma)$ & $15.2 \mathrm{kN} / \mathrm{m}^{3}$ \\
\hline Angle of repose $(\varnothing)$ & $17.5^{\circ}$ \\
\hline Ultimate tensile strength & $7.25 \times 10^{3} \mathrm{kN} / \mathrm{m}^{3}$ \\
\hline Modulus of Elasticity & $25000 \times 10^{3} \mathrm{kN} / \mathrm{m}^{3}$ \\
\hline Poisson's ratio & 0.2 \\
\hline Bulk modulus & $13889 \times 10^{3} \mathrm{kN} / \mathrm{m}^{3}$ \\
\hline Shear Modulus & $10417 \times 10^{3} \mathrm{kN} / \mathrm{m}^{3}$ \\
\hline
\end{tabular}

\section{RESULTS AND DISCUSSIONS}

The results presented below analysis the variation in static pressure. The horizontal pressure $\left(\mathrm{P}_{\mathrm{h}}\right)$ and vertical pressure $\left(\mathrm{P}_{\mathrm{v}}\right)$ correspond to longitudinal and hoop stresses are calculated and presented in this paper. The silo was assumed to be fixed at ring beam level and the calculated load components $\mathrm{P}_{\mathrm{h}}$ and $\mathrm{P}_{\mathrm{v}}$ by Janssen's method were applied on the wall of silo.[10] The maximum tensile stresses were considered within limiting criteria for the analysis of ferrocement composite. The different capacities of $600 \mathrm{~m}^{3}$, $500 \mathrm{~m}^{3}$, and $400 \mathrm{~m}^{3}$ were considered. The different height to diameter ratio (H/D) considered were 3,4, and 5. Variation of $\mathrm{P}_{\mathrm{h}}$ and $\mathrm{P}_{\mathrm{v}}$ with respect to height for various capacities and $\mathrm{H} / \mathrm{D}$ ratios is shown in Table 2.

Table- II: Maximum values of hoop and longitudinal stresses for various capacities

\begin{tabular}{|c|c|c|c|}
\hline $\begin{array}{c}\text { Volumes } \\
\mathbf{( m}^{\mathbf{3}} \mathbf{)}\end{array}$ & $\mathbf{H} / \mathbf{D}$ & $\begin{array}{c}\text { Longitudinal } \\
\text { stress } \mathbf{~ k P a}\end{array}$ & $\begin{array}{c}\text { Hoop stress } \\
\mathbf{k P a}\end{array}$ \\
\hline 600 & 5 & $63 \times 10^{3}$ & $4.82 \times 10^{3}$ \\
\hline 500 & 5 & $41 \times 10^{3}$ & $4.31 \times 10^{3}$ \\
\hline 400 & 5 & $36.6 \times 10^{3}$ & $3.84 \times 10^{3}$ \\
\hline 600 & 4 & $46.6 \times 10^{3}$ & $5.31 \times 10^{3}$ \\
\hline 500 & 4 & $39 \times 10^{3}$ & $4.52 \times 10^{3}$ \\
\hline 400 & 4 & $37.2 \times 10^{3}$ & $4.36 \times 10^{3}$ \\
\hline 600 & 3 & $42.8 \times 10^{3}$ & $5.88 \times 10^{3}$ \\
\hline 500 & 3 & $4.4 \times 10^{3}$ & $4.96 \times 10^{3}$ \\
\hline 400 & 3 & $35.5 \times 10^{3}$ & $4.54 \times 10^{3}$ \\
\hline
\end{tabular}

The Finite Element model was developed considering Tetrahedral mesh elements (5 node -Tet elements). Free mesh was adopted as meshing style as shown in Figure 1.

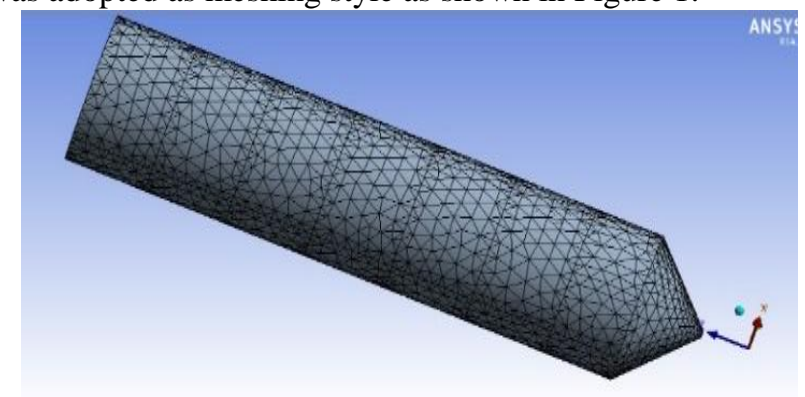

Figure1: Mesh formation.

Published By:

Blue Eyes Intelligence Engineering 
The distribution of hoop stresses over the silo wall by finite elements (FE) models are shown in Figures 2-a to 2-i. Graphical variation of hoop stress vs height for various capacities and H/D are presented in Figures 4-a to 4-c. It can be observed that, static pressure shows a similar distribution to the distribution by Janssen's equation. Maximum hoop pressure is observed at the bottom silo which goes on increasing from top to bottom over the height in longitudinal direction. Also, the distribution of longitudinal stresses over the silo wall by (FE) models are shown in Figures 3-a to 3-i. Graphical variation of longitudinal stress vs Height for various capacities and H/D are presented in Figures 5-a to 5-c. Also, the longitudinal stresses go on increasing with height from top to bottom.

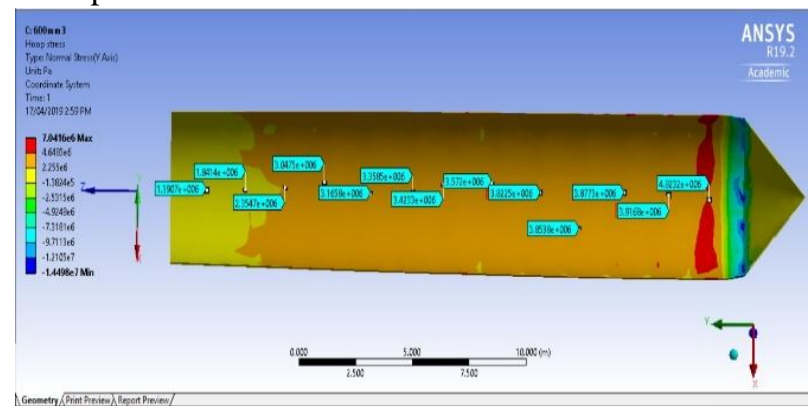

Figure 2-a: Hoop stress distribution, $600 \mathrm{~m}^{3}$ and $\mathrm{H} / \mathrm{D}=\mathbf{5}$.

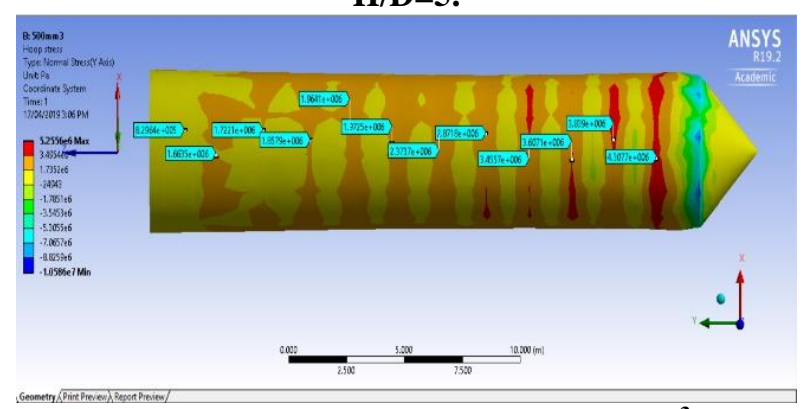

Figure 2-b: Hoop stress distribution, $500 \mathrm{~m}^{3}$ and $\mathrm{H} / \mathrm{D}=5$.

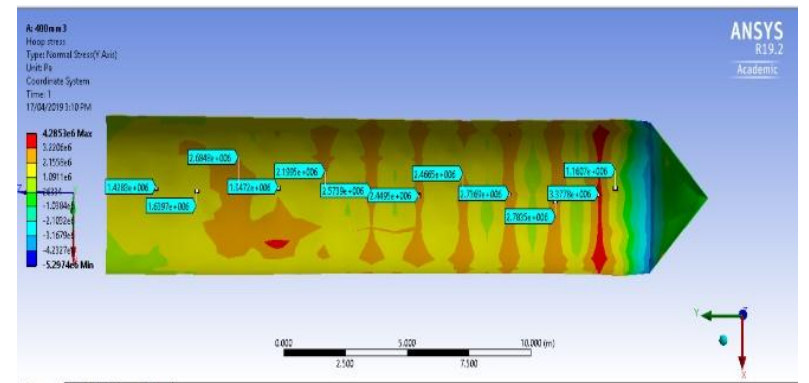

Figure 2-c: Hoop stress distribution, $400 \mathrm{~m}^{3}$ and $\mathrm{H} / \mathrm{D}=5$.

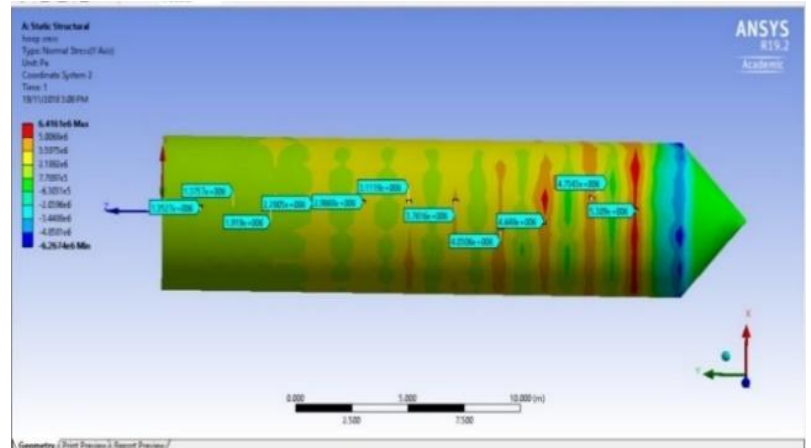

Figure 2-d: Hoop stress distribution, $600 \mathrm{~m}^{3}$ and $\mathrm{H} / \mathrm{D}=\mathbf{4}$.

Published By:

Blue Eyes Intelligence Engineering \& Sciences Publication

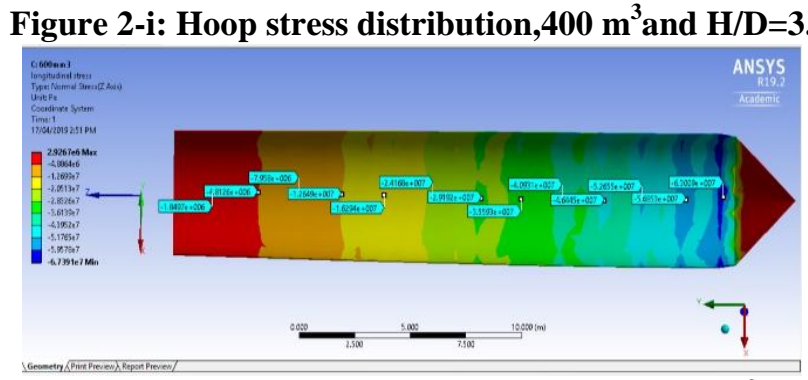

Figure 3-a: Longitudinal stress distribution, $600 \mathrm{~m}^{3}$ and $H / D=5$. 


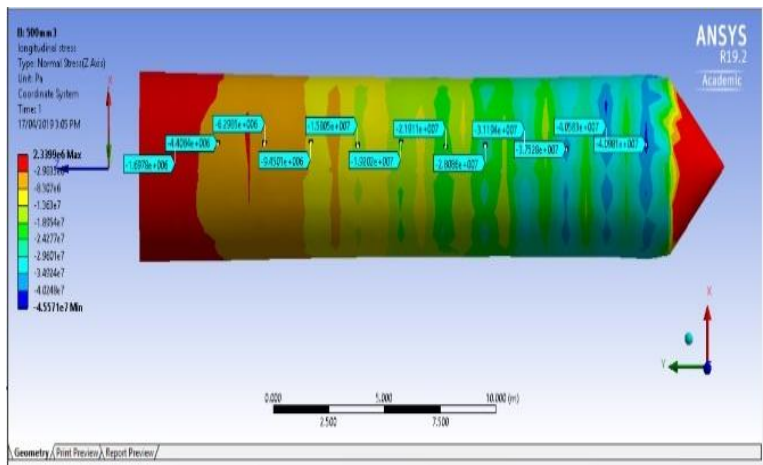

Figure 3-b: Longitudinal stress distribution,500m3 and $H / D=5$.

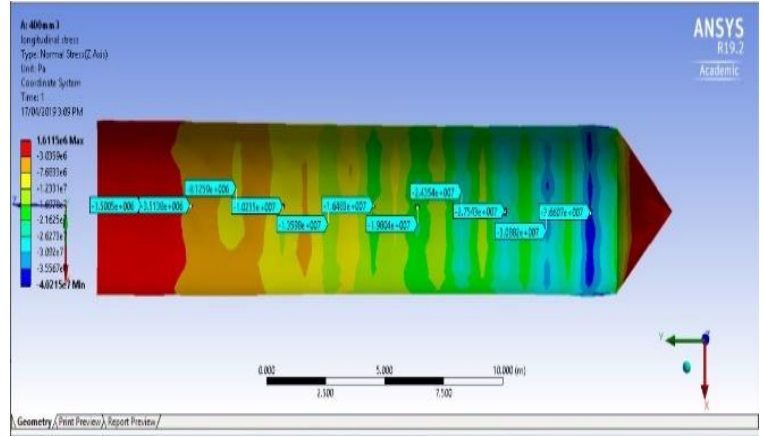

Figure 3-c: Longitudinal stress distribution, $400 \mathrm{~m}^{3}$ and $\mathbf{H} / \mathbf{D}=5$.

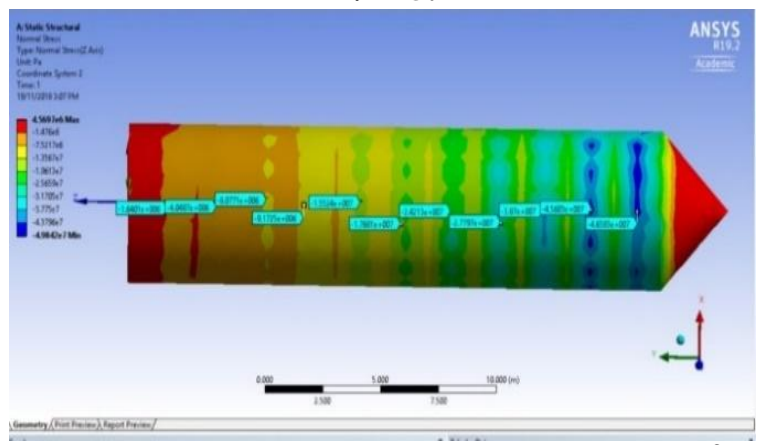

Figure 3-d: Longitudinal stress distribution, $600 \mathrm{~m}^{3}$ and $\mathrm{H} / \mathrm{D}=\mathbf{4}$

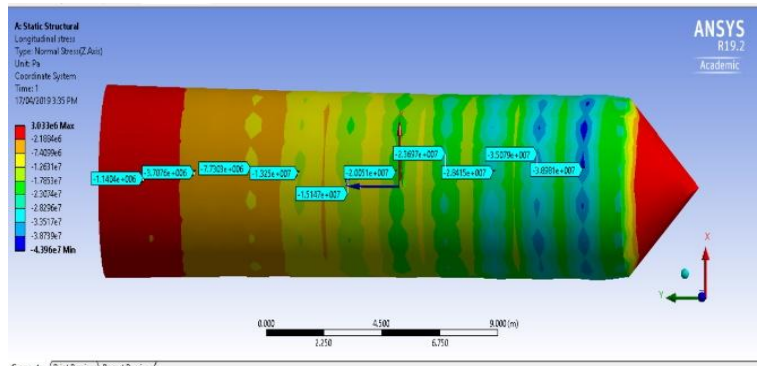

Figure 3-e: Longitudinal stress distribution, $500 \mathrm{~m}^{3}$ and $\mathrm{H} / \mathrm{D}=\mathbf{4}$.

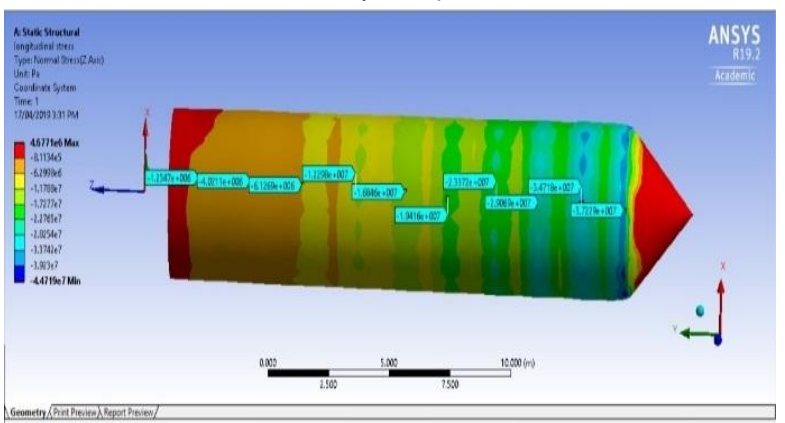

Figure3-f: Longitudinal stress distribution, $400 \mathrm{~m}^{3}$ and $\mathrm{H} / \mathrm{D}=\mathbf{4}$.

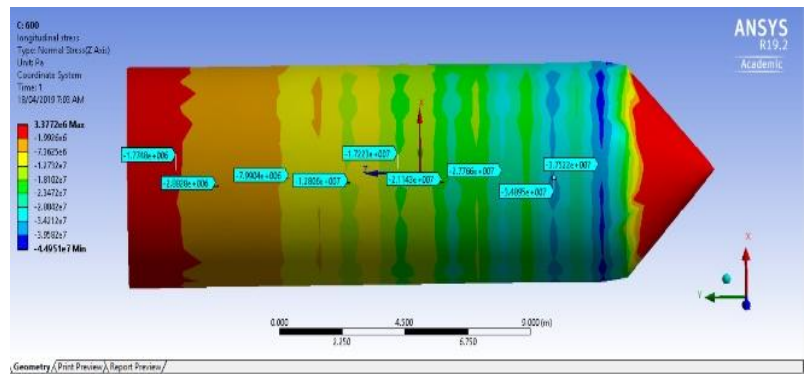

Figure 3-g: Longitudinal stress distribution, $600 \mathrm{~m}^{3}$ and $\mathrm{H} / \mathrm{D}=3$.

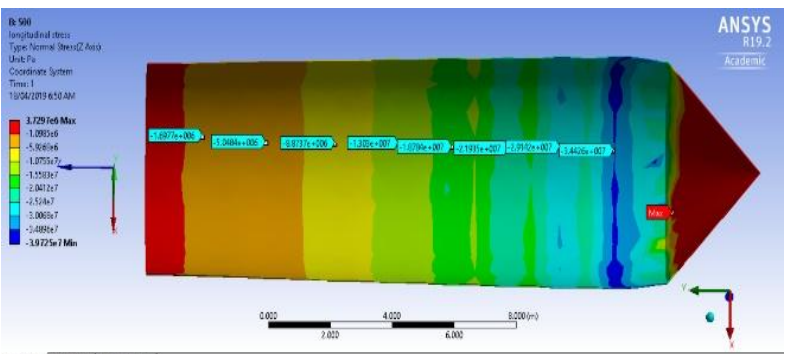

Figure 3-h: Longitudinal stress distribution,.500 $\mathrm{m}^{3}$ and $\mathbf{H} / \mathbf{D}=3$.

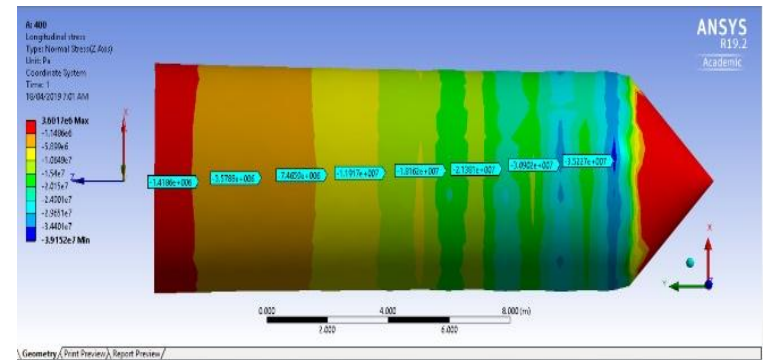

Figure 3-i: Longitudinal stress distribution, $400 \mathrm{~m}^{3}$ and $\mathrm{H} / \mathrm{D}=3$.

The variation of hoop stresses on the cylindrical silo wall with respect to height of silo for various capacities and H/D ratio is presented below in Figure 4. The variation of hoop stresses on silo wall were superimposed and graphically shown for different H/D ratio. It is observed that initially hoop stresses are increased exponentially and then for rest of the height the curve follows asymptoticly. It also shows clearly with increase in H/D ratio hoop stresses are decreases in wide range for the same capacity. Also, quit lower value is noticed with increase in $H / D$ ratio for the same capacity Figure 4.

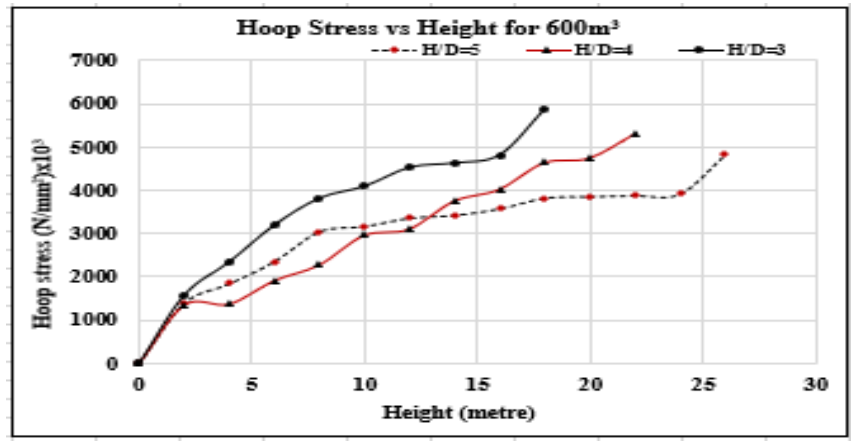

Figure 4-a: Variation of Hoop stress vs Height for various H/D-600 $\mathrm{m}^{3}$.

Published By:

Blue Eyes Intelligence Engineering

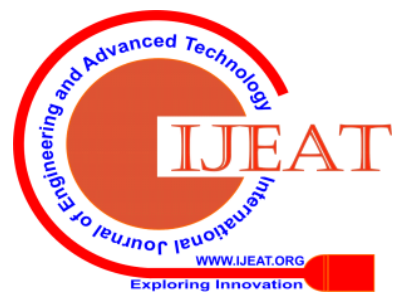




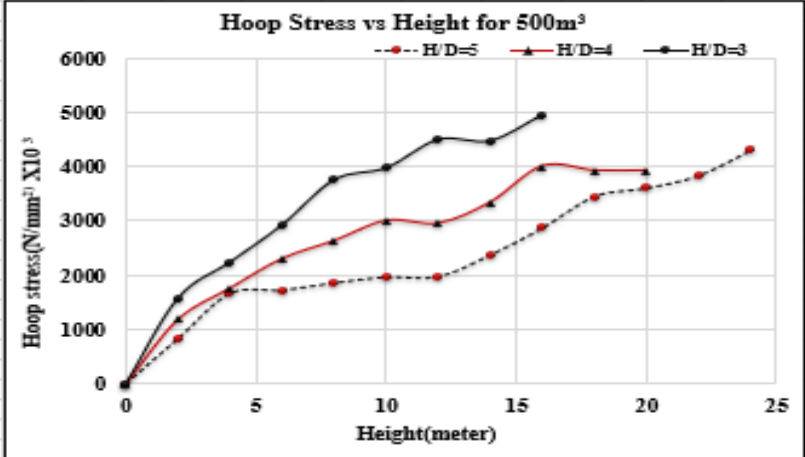

Figure 4-b: Variation of Hoop stress vs Height for various H/D-500 $\mathrm{m}^{3}$.

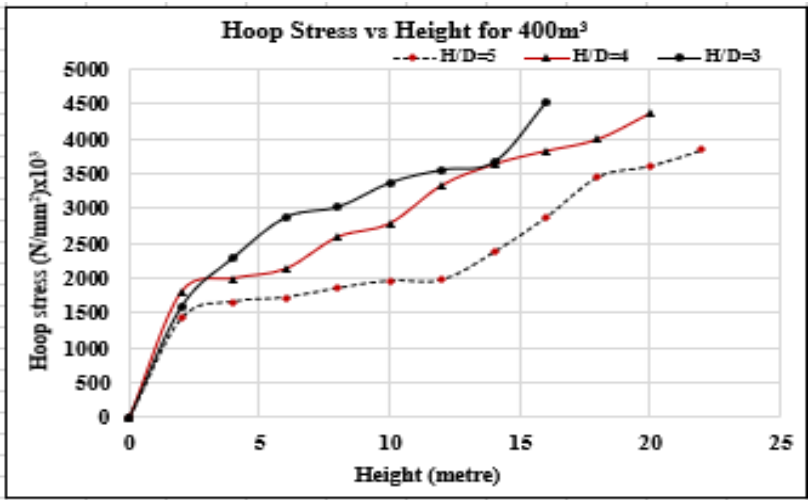

Figure 4-c: Variation of Hoop stress vs Height for various $H / D-400 \mathrm{~m}^{3}$.

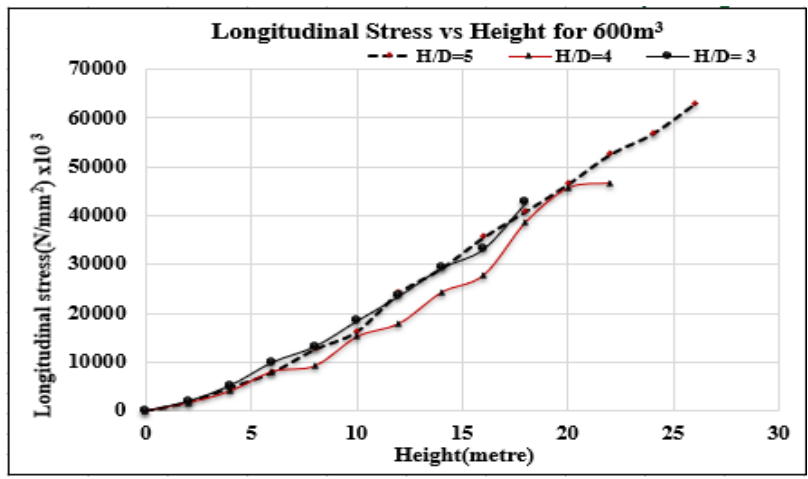

Figure 5-a: Variation of Longitudinal stress vs Height for various $H / D-600 \mathrm{~m}^{3}$.

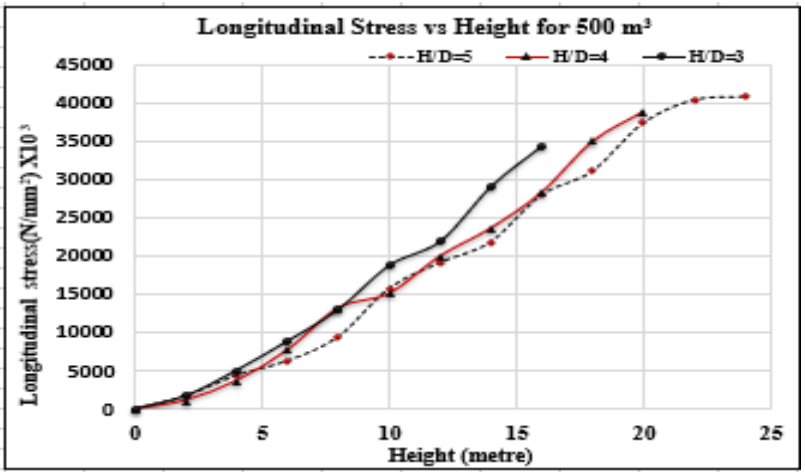

Figure 5-b: Variation of Longitudinal stress vs Height for various $\mathbf{H} / \mathbf{D}-\mathbf{5 0 0} \mathrm{m}^{3}$.

Also, the variation of longitudinal stresses vs height of silo for various capacities and H/D ratio is presented below in Figure 5. The variation of longitudinal pressure on silo wall were superimposed and graphically shown for different H/D. It is observed that with increase in $\mathrm{H} / \mathrm{D}$ ratio longitudinal stresses are increased.

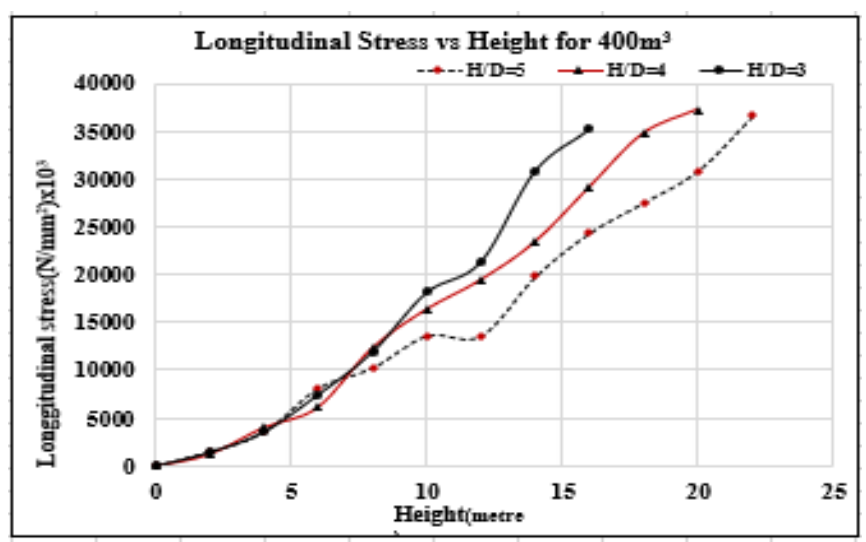

Figure 5-c: Variation of Longitudinal stress vs Height for various $\mathrm{H} / \mathrm{D}-\mathbf{4 0 0} \mathrm{m}^{3}$.

The static models for F.C. silos are shown below, the variation of the hoop and Longitudinal stresses on the wall compares very well with those obtained by means of traditional theories and international standards [Figure 12]. As shown in figures the hoop stress varies initially exponentially and then becomes asymptote. [11,12]

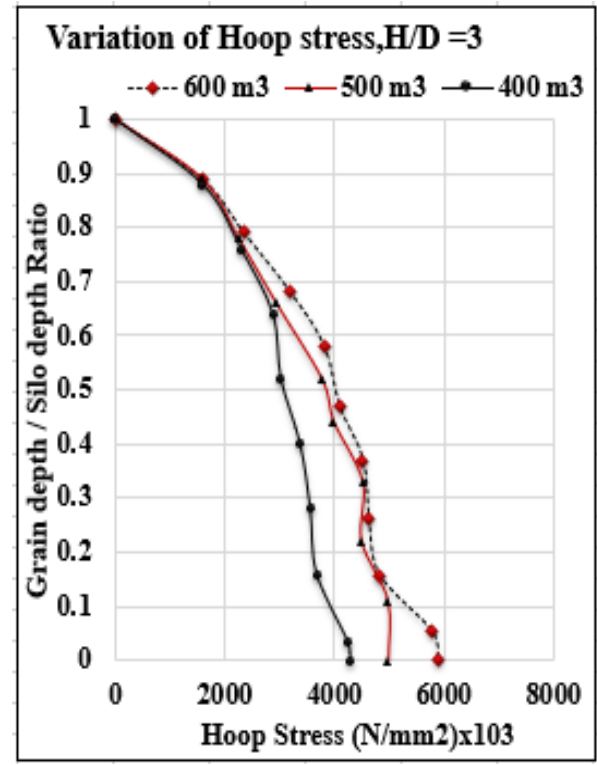

Figure 6: Variation of Hoop stress vs Silo Depth/ Grain Depth Ratio for $H / D=3$

The hoop stresses obtained from numerical models and by analytical equation are compared in [ Figure 6-11]. In

analytical equation, the hoop stress occurred in cylindrical silo increases exponentially with depth and reaches asymptoticly, which observed in numerical models. Variation of hoop stresses with analytical equation shows a good agreement with the numerical model results. Adherence in both the results could be seen in [ Figure 6-11]. But there is some deviation at the vicinity of ring beam level. In numerical model, hoop stresses distribution gives slightly upper values. Since in analytical equation tends to underestimate the hoop stresses with incorporating additional parameters such as dilation angle in the analytical formulation may improve in the predictions.
Published By:

Blue Eyes Intelligence Engineering

\& Sciences Publication

(C) Copyright: All rights reserved.

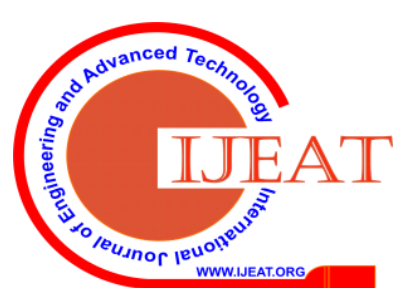




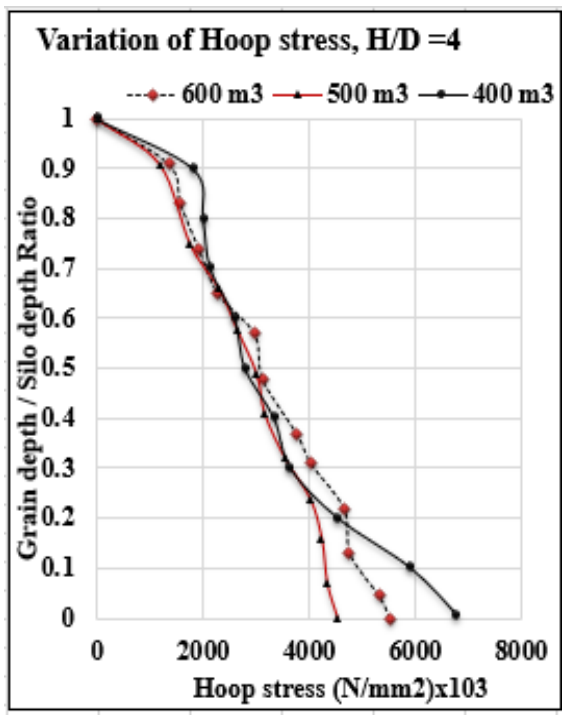

Figure 7: Variation of Hoop stress vs Silo Depth/ Grain Depth Ratio for $H / D=4$

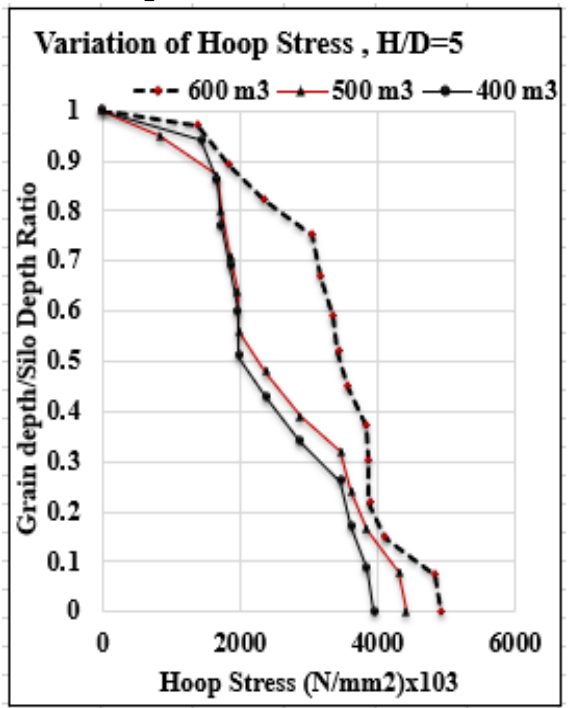

Figure 8: Variation of Hoop stress vs Silo Depth/ Grain Depth Ratio for $\mathrm{H} / \mathrm{D}=5$

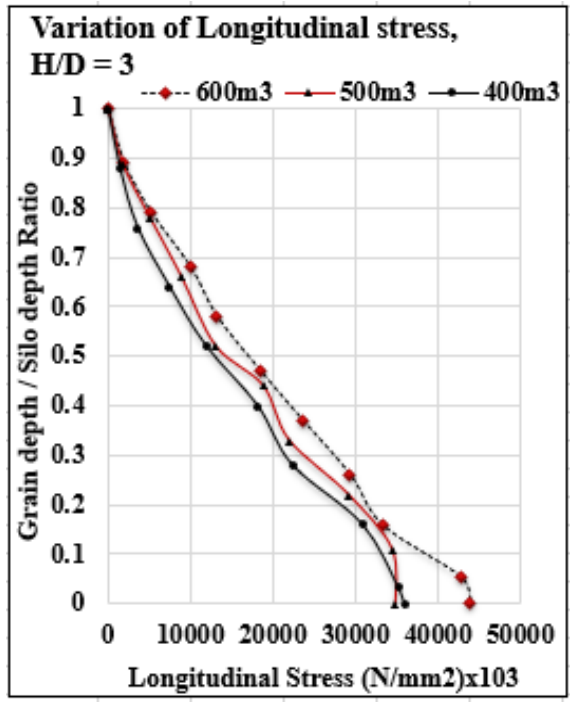

Figure 11: Variation of Longitudinal stress vs Silo Depth/ Grain Depth Ratio for $H / D=3$

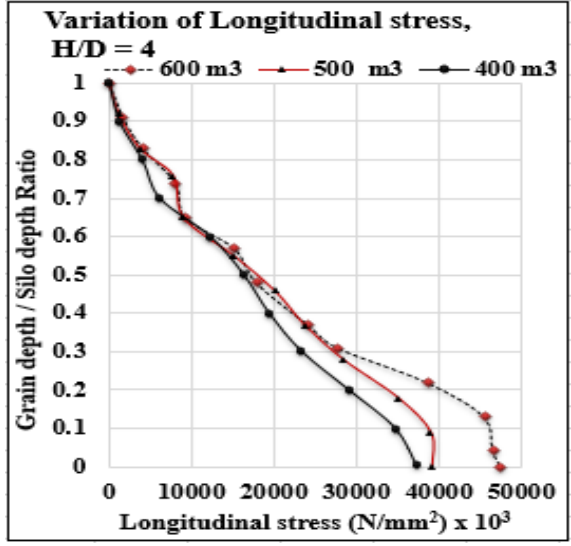

Figure 9: Variation of Longitudinal stress vs Silo Depth/ Grain Depth Ratio for $\mathrm{H} / \mathrm{D}=\mathbf{4}$

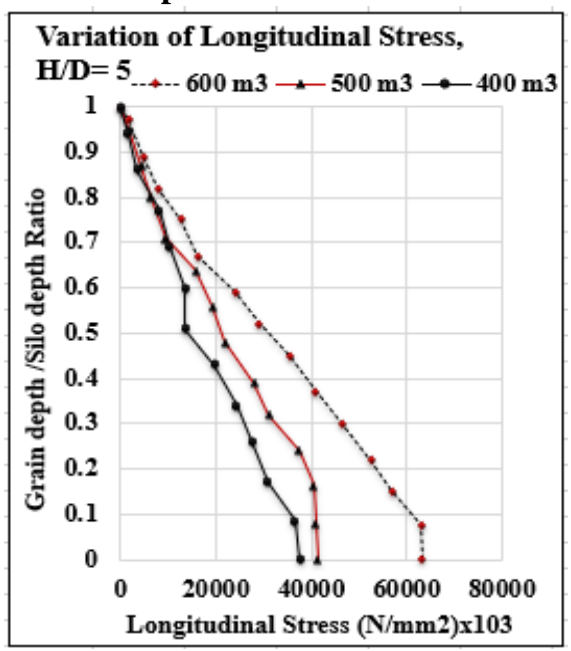

Figure 10: Variation of Longitudinal stress vs Silo Depth/ Grain Depth Ratio for $\mathrm{H} / \mathrm{D}=5$

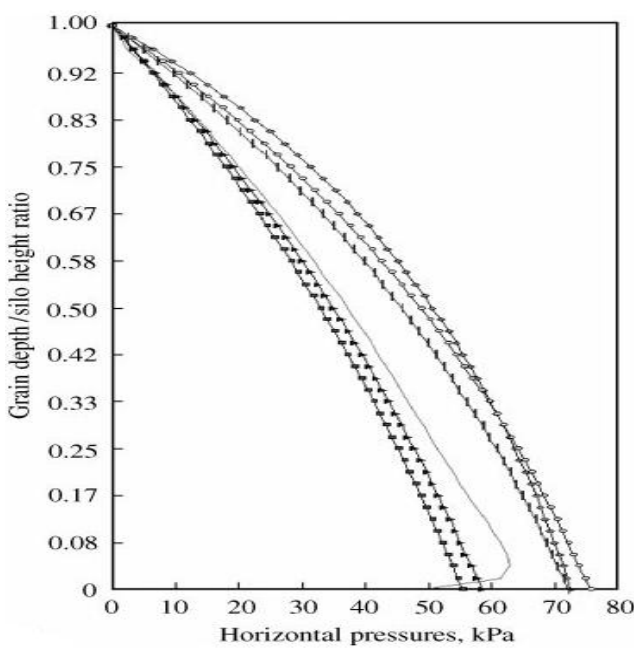

Finite element method, $\longrightarrow$ Caquot and Kerisel (1956), $\longrightarrow$ Janssen (1895), $\longrightarrow$ Reimbert and Reimbert (1980), $\longrightarrow$ Eurocode) (1995) DIN 1055-6 (1987).

Figure 12: Variation of Hoop stress vs Silo Depth/ Grain Depth Ratio by traditional theories and international standards [12].

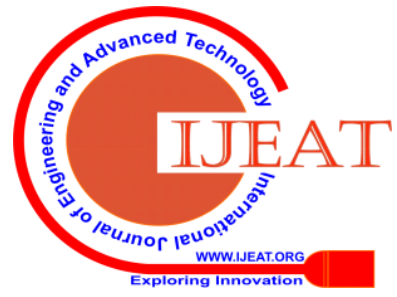




\section{CONCLUSIONS}

The analysis for static and dynamic loading is possible. However, the static condition of material at rest is presented in this paper. For both statics condition and centralized discharge, finite elements models capable of simulation the behavior of silo stored material was developed. The walls of ferrocement silo with fixed conical hopper was analyzed for central axi-symmetrical discharge. The material stored in silo was considered as cement. In these models, parameters such as capacities of silo and various H/D ratios was considered which gives a great influence on longitudinal and hoop pressure. It is evident from Figure 6-11 that the nature of curve validates the relationship of longitudinal stress and hoop stress with the H/D ratio for various capacities of F.C. silo. Maximum longitudinal pressure is observed at the bottom silo which goes on increasing from top to bottom over the height in longitudinal direction. Also, the hoop stress goes on increasing with height from top to bottom. It is observed that with increase in H/D ratio hoop stresses are decreases and with increase in H/D ratio longitudinal stresses are increased. Work is validated with number of research numerical models given by Janssen, Caquite, Riembert, Eurocode and F. Ayuga as shown in Figure 12. The overpressure of longitudinal stress has been attributed at the junction of silo and hopper ring beam which validates the "elephant foot stress effect" [13].

\section{REFERENCES}

1. Naaman, A. E. Research to practice: The case of Ferrocement, Research transformed into practice, pp-649-650.

2. ACI committee, 549,1R-93. Guide for the design, construction and repair of Ferrocement, American concrete institute.

3. ACI committee, 549,1R-97. State-of- art report on Ferrocement, American concrete institute.

4. Digvir Singh., E.B. Moyes, Grain bin wall pressure: Theoretical and experimental. Canadian agricultural engineering, 1985 vol. 27 No.1 pp-43-48.

5. C.V. Schwab; I. J. Ross; G. M. White; D.G. Colliver, Wheat loads and vertical pressure distribution in a full- scale bin pare-I-Filling. American Society of Agricultural Engineers, $1994 \mathrm{vol}$ 37(5):1613-1619.

6. Parisi D. R.; Masson, S Martinez J, Partitioned distinct element method simulation of granular flow within industrial silos, journal of engineering mechanics, vol. 130, No. 7, July 1, 2004. (CASCE, 2004/7-771-779, pp- 771-779.

7. Chen, J. F.; Yu, S. K.; Ooi, J. Y.; Rotter, J. M, Finite -element modeling of filling pressures in a full-scale silo, journal of engineering mechanics, Vol. 127, No. 10, October, 2001. ASCE, ISSN0733-9399/01/0010- pp-1058-1066 paper No. 22737.

8. Islam M. Ezz El- Arab, Seismic analysis of RC Silos dynamic discharge phenomena. International Journal of engineering and advanced technology (IJEAT), 2014 ISSN: 2249-8958m vol. 4, Issue-2. December 2014.

9. J. Mark F., G. Holst., Jin Y. Ooi., J. Michael Rotter., Graham H. Rong, Numerical modeling of silo filling. I: continuum analyses. Journal of engineering mechanics, vol. 125, No. 1, ASCE, 1999, ISSN 0733-9399/99/0001- pp- 94-103. paper No. 17703.

10. Haken Kibar, Patterns between wall pressures and stresses with moisture on cylindrical silo. Structural Engineering and Mechanics, 2017 Vol. 62, No. 4, 487-496.

11. Sankha Widisinghe, Nagaratnam Sivakugan, Vertical Stresses within Granular Materials in Silos. ANZ Conference Proceedings, 2012, PP590-594.

12. F Ayuga., M. Guaita., P. Aguado. Static and dynamic silo load using finite element models, structures and environment, J. agric. Eng. Res. 2001, 78 (3), pp- 299-308.

13. Sadowski A.J, Rotter J. M. A study of buckling in steel silos under eccentric discharge flows of stored solids. ASCE Journal of Engineering Mechanics 1943;136(6):69-776.

Blue Eyes Intelligence Engineering

\& Sciences Publication

\section{AUTHORS PROFILE}

\section{P. Patel}

Associate Professor, Civil Engineering Department, College of Engineering Shahada, Maharashtra, India, having teaching experience of 30 years and research area in finite elements analysis.

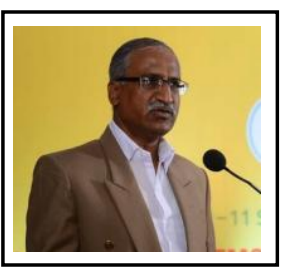

Sunil Kute.

Professor, Department of Civil Engineering K K. Wagh Institute of Engineering Education and Research, having teaching experience of 28 years, working as an academic dean of University of Pune, Maharashtra India,

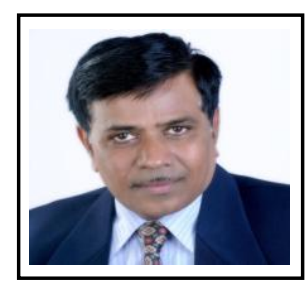

P.D. Patil.

Principal, Jaykumar Raval Institute of Technology Dondaicha, Maharashatra, India. Acadamic administration as Principal for 24 years, completed his PhD. from RGPU Bhopal in 2010 .

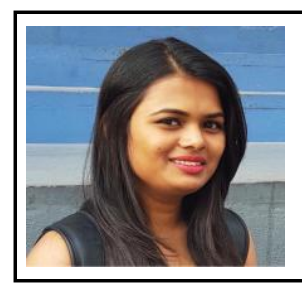

\section{Renuka Jain.}

Graduate student, Department of Civil Engineering College of Engineering Shahada, Maharashtra, India. 